\title{
Introduction of New Editorial Board Members and Appointment of New Associate Editor
}

\author{
Phillip Lupo, Jr., MLIS, Anne Victoria Neale, PhD, MPH, \\ and Marjorie A. Bowman, MD, MPA
}

In this issue we feature our newest editorial members of the Journal of the American Board of Family Medicine. In addition, we announce the appointment of Editorial Board member Dean Seehusen, MD, MPH, to Associate Editor. We take this opportunity to welcome all our new editorial board members to the JABFM and congratulate Dr. Seehusen on his new appointment. (J Am Board Fam Med 2014;27:4-5.)

Dean Seehusen, MD, MPH, Associate Editor

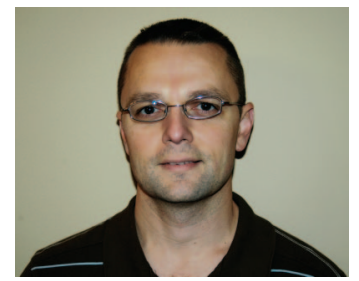

Dr. Dean Seehusen earned his medical degree from the University of Iowa and a master's of public health from the University of Washington. He is a graduate of the Tripler Army Medical Center Family Medicine Residency and the Madigan Army Medical Center Faculty Development Fellowship in Family Medicine. He holds a board certification from the American Board of Family Medicine and has an active license to practice medicine in Hawaii. Dr. Seehusen is a diplomate and fellow of the American Academy of Family Physicians (AAFP). Dr. Seehusen is currently chair of the AAFP Commission on Continuing Development Subcommittee on Clinical Content and Accreditation, a contributing editor to American Family Physician, and an editorial board member of Family Medicine. Dr. Seehusen is currently the program director of the Family Medicine Residency at the Fort Belvoir Community Hospital in Fort Belvoir, VA.

\section{Nancy C. Elder, MD, MSPH, Editorial Board Member}

Dr. Nancy Elder is professor of Family and Community Medicine and director of research at the University of Cincinnati. She also directs a regional

Conflict of interest: The authors are editors and staff of the JABFM.

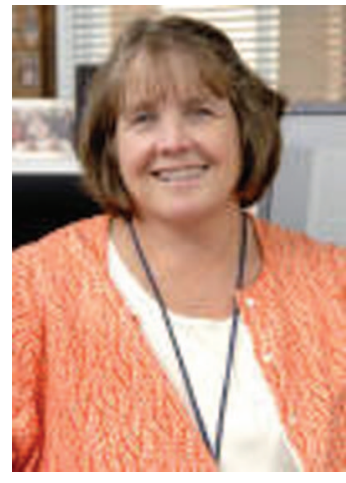

practice-based research network, the Cincinnati Area Research and Improvement Group (CARInG). Her research interests are in quality and patient safety in primary care. She teaches medical and graduate students and directs family medicine residents in performing community partnered research projects. Her clinical practice is with the Cincinnati Health Care for the Homeless program.

\section{Jennifer E. DeVoe, MD, DPhil, Editorial Board} Member

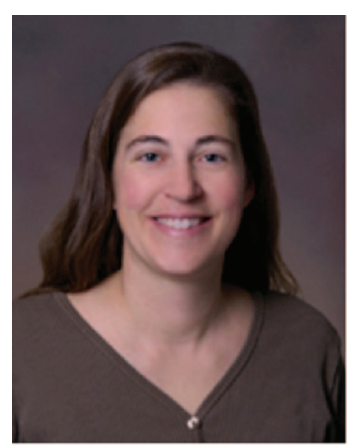

Dr. Jennifer (Jen) DeVoe received an MD from Harvard Medical School and completed her Family Medicine residency at Oregon Health \& Science University (OHSU). As a Rhodes Scholar, she completed an MPhil and DPhil in economic and social history at Oxford University. She is currently an associate professor in the OHSU Department of Family Medicine, with research interests in access to care and health outcomes for low-income populations. Dr. DeVoe also serves as the executive 
director of the OCHIN PBRN. She is an author of more than 80 peer-reviewed publications. In addition to her busy portfolio of research, she also sees patients at the OHSU Gabriel Park Family Medicine Center and precepts medical students and residents.

\section{Chyke A. Doubeni, MD, MPH, Editorial Board Member}

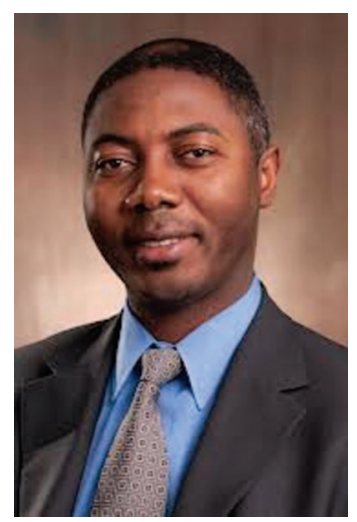

Dr. Chyke Doubeni is Presidential Associate Professor (C-E) of Family Medicine and Community Health and Associate Professor of Epidemiology at the Perelman School of Medicine at the University of Pennsylvania. Dr. Doubeni is board certified in both family medicine and general preventive medicine/public health and currently serves as the vice chair for research in the Department of Family Medicine and Community Health at the University of Pennsylvania. In 2009 to 2010 he served as interim Associate Vice Provost for Diversity at the University of Massachusetts Medical School. Dr. Doubeni is a senior scholar at the Center for Clinical Epidemiology and Biostatistics and a senior fellow at both the Leonard Davis Institute of Health Economics and the Center for Public Health Initiatives at Penn and a full member of the Abramson Cancer Center, a National Cancer Institute Comprehensive Cancer Center, at the University of Pennsylvania. In 2010 he received a Presidential Early Career Award for Scientists and Engineers. Dr. Doubeni's research focuses primarily on colorectal cancer.

\section{Zsolt J. Nagykaldi, PhD, Editorial Board Member}

Dr. Zsolt Nagykaldi is Associate Professor and Associate Director of Research in the Department of Family and Preventive Medicine at the University of Oklahoma Health Sciences Center. He is also

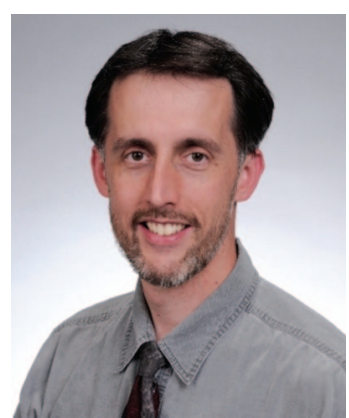

the administrative director of the Oklahoma Physicians Resource/Research Network (OKPRN). He holds a BS in pharmacy and a $\mathrm{PhD}$ in pharmacology. Dr. Nagykaldi has participated in a 2-year master's-level public health and health services research didactic curriculum. Since 2001 he has been working closely with a network of community primary care practices throughout Oklahoma to improve the quality and safety of care through participatory practice-based health services research. His current work includes the development and testing of a novel, patient goaldirected, prospective care delivery approach via a web-based health risk appraisal tool. Dr. Nagykaldi is a regular reviewer for a number of primary care peer-reviewed journals and sits on various study sections at Agency for Health care Research and Quality and international research organizations.

\section{Sarina Schrager, MD, Editorial Board Member}

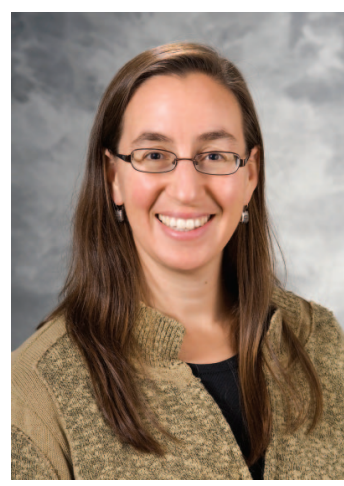

Dr. Sarina Schrager completed medical school at the University of Illinois, Chicago. She then completed a family medicine residency and primary care women's health fellowship at MacNeal Hospital in Berwyn, IL. She joined the faculty in the Department of Family Medicine at the University of Wisconsin School of Medi-

cine and Public Health in 1996. She completed an MS in epidemiology in 2008 at the University of Wisconsin. She has spent the past 17 years teaching residents about women's health in primary care. Her research interests include work-life balance, primary care for women, and osteoporosis prevention. 